\title{
A rare presentation of bronchogenic cyst as dysphagia
}

\author{
Girish Rai $^{1}$, Kavitha Palled ${ }^{2, *}$, Divyashree Manjunath ${ }^{3}$ \\ ${ }^{1}$ Senior Consultant, ${ }^{2}$ Senior Registrar, ${ }^{3}$ Junior Resident, Dept. of ENT, Manipal Hospital, Bangalore, Karnataka, India
}

*Corresponding Author:

Email: bkkavitha001@gmail.com

\section{Introduction}

Bronchogenic cysts are congenital foregut malformations that develop due to abnormal budding of the embryonic foregut and tracheobronchial tree. They are usually mediastinal or intrapulmonary, but can rarely be located in the lower neck. The mediastinal location is more common, and bronchogenic cysts comprise of up to $40-50 \%$ of all congenital mediastinal cysts. ${ }^{1}$ Although bronchogenic cysts are usually detected incidentally, $45 \%$ of patients will develop symptoms in their lifetime. This may be related to the location of the cyst rather than cyst size; cysts located above the hilum pose a higher risk for compressive symptoms. ${ }^{2,3}$

We report a case of paratracheal air cyst causing dysphagia, which was ultimately treated by surgical resection.

\section{Case Report}

A 36-year old man presented to our department of ENT and Head \& Neck Surgery with a 4-week history of dysphagia, more for solids. There were no associated symptoms. Clinical examination was unremarkable. Blood tests showed a normal full blood count and differential,electrolytes, liver enzymes . Barium swallow (Fig. 1) demonstrated filling defect on the right upper cervical oesophagus. A subsequent computed tomography (CT) scan of neck with contrast revealed a well defined air containing cystic lesion of size $2.4 \times 1.5 \times 2.7 \mathrm{~cm}$ in right paratracheal region at the level of D1 and D2 vertebra levels (thoracic outlet) with no evidence of communication with trachea, and oesophagus being displaced to the left (Fig. 2 and 3) consistent with a bronchogenic cyst (BC). The cyst was seen to compress the oesophagus, accounting for the patient's symptom of dysphagia.

Following the assessment by cardiothoracic surgeons, the patient underwent cyst excision without thoracotomy (Fig. 4) which resulted in complete resolution of his symptoms. On histopathological examination, the cyst was lined with ciliated pseudostratified columnar epithelium overlying a layer of discontinuous smooth muscle and an outer wall composed of fibrovascular connective tissue (Fig. 5). These findings were consistent with a bronchogenic cyst.

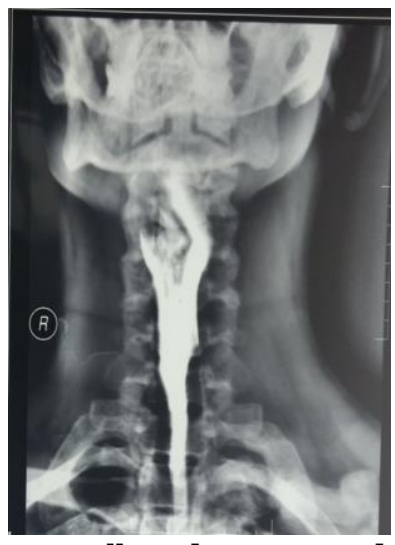

Fig. 1: Barium swallow demonstrated filling defect on the right upper cervical oesophagus
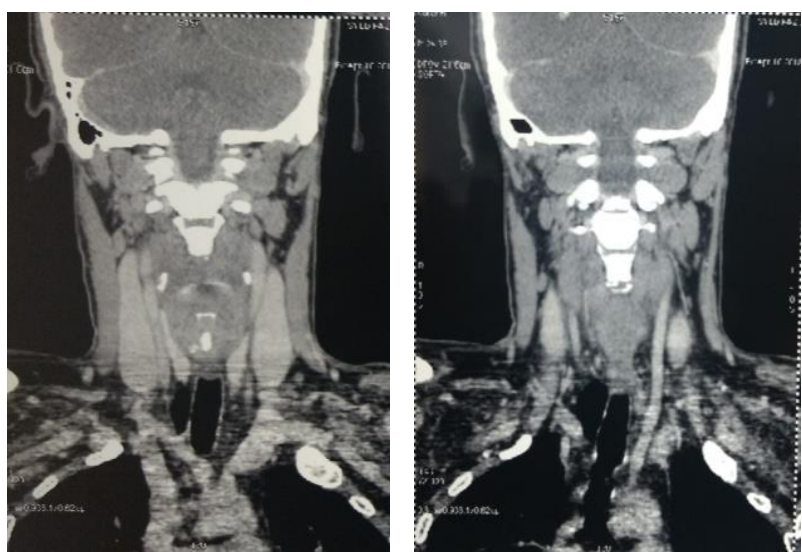

Fig. 2 \& 3: Computed tomography (CT) scan of neck with contrast showing a well defined air containing cystic lesion in right paratracheal region at the level of D1 and D2 vertebra

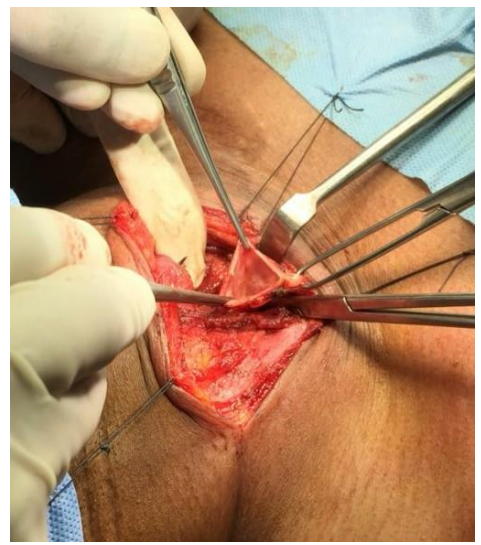

Fig. 4: Right paratracheal cyst being excised 


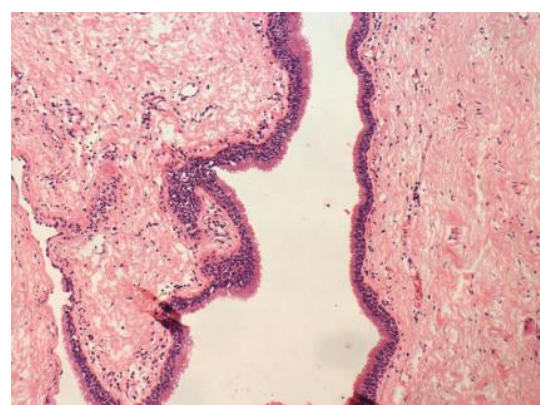

Fig. 5: cyst lined with ciliated pseudostratified columnar epithelium overlying a layer of discontinuous smooth muscle and an outer wall composed of fibrovascular connective tissue

\section{Discussion}

In accordance with Kumar et al., the bronchogenic cyst was first described by Blackader in 1911. However, it was not until 1948 when Maier performed the first surgical resection. ${ }^{4}$ The bronchogenic cyst is a remnant of the primitive foregut, secondary to tracheabronchial malformations. In 2001, ${ }^{5}$ Bush described it as a congenital pulmonary malformation and that it represented from $14 \%$ to $22 \%$ of congenital pulmonary malformations and $10 \%$ of mediastinal malformations. Bronchogenic cysts are generally communicated with the trachea-bronchial tree through an accessory bronchus or through the oesophagus. They may be single or multiple, asymptomatic or symptomatic and when they are found in the neck they may be associated with a vertebral malformation. ${ }^{5,6}$ Approximately from $65 \%$ to $86 \%$ are mediastinal (median and posterior mediastinum), and of these they may be adjacent to the distal third of the trachea or close to the main bronchus. From here they may subdivide into pericardiac (52\%), paratracheal (19\%), paraoesophagic (14\%) and retrocardiac (9\%), and the majority are on the right. ${ }^{6}$ The majority are asymptomatic, but when they present symptoms this is due to communication with the trachea, compression of the oesophagus (dysphagia), to recurrent infections (75\% of cases), haemoptysis as the only symptom, fever, coughing, cardiac arrhythmias, right cardiac failure, recurrent pericarditis or compression of the superior vena cava. ${ }^{7}$ Infrequent locations are: neck, pericardium, abdominal cavity and subcutaneous regions. Although they are more frequent in the mediastinum, occasionally they are not visible with chest teleradiography, but may be appreciated as a mediastinal or hiliary tumour; the intrapulmonary muscles are more frequently seen in inferior lobules (75\% of cases). When it is not possible to see the lesion, computerised tomography of the neck or chest shows the presence of lesions in $50 \%$ of cases and these have defined sides, thin walls and a density of liquid ${ }^{8}$ (\#\#---20 and +20UH); in the other 50\% of cases there is a mucoid density. Depending on size, this may or may not compress structures such as the oesophagus and trachea, or affect atelectases. It is also possible to perform MRI. The cysts show up as hypointense lesions in $\mathrm{T} 1$ and hyperintense lesions in T2. ${ }^{8}$ Histologically, the bronchogenic cysts present a thin wall (when not infected), with ciliated columnar epithelium, similar to that covering the bronchials. Furthermore, they may contain cartilage, muscles, nerve tissue or bronchial glands, which contain a clear or mucous liquid. ${ }^{6,9}$ Bronchogenic cysts should be differentiated from other median and posterior mediastinum masses (Bush, 2001), including goitre, teratomas, tumours (thy

mic, germinal and neurogenic) and pulmonary tumours, or diaphragmatic hernias, lymphagiomas, hemangiomas, oesophagic duplication, pericardium cysts, or enteric cysts. Treatment even in asymptomatic patients is surgical to prevent complications such as pulmonary infections, compression of structures and malignant transformation. The differential diagnosis of an air-filled paratracheal region includes a laryngocele, a pharyngocele, a Zenker's diverticulum, tracheal diverticula, third and fourth branchial anomalies, paraseptal bullae, and apical lung herniations 10, 11 . Radiological barium swallow study, endoscopic techniques, and CT can be used to characterize the lesion. For example, differentiation of Zenker's diverticulum from paratracheal air cyst can often be accomplished by demonstrating a communication between the cyst and the digestive tract or lung apex using barium swallow and axial imaging studies. ${ }^{10}$

\section{Conclusion}

Although a paratracheal air cyst /bronchogenic cyst is commonly asymptomatic and detected incidentally, there are rare reports of paratracheal air cysts presenting with chronic cough, repeated episodes of respiratory infections, hemoptysis, stridor or dyspnea, dysphagia. The symptomatology of a bronchogenic cyst is due to the compression of the vascular, digestive or air structures, as well as its size, infection and location. In our case, the paratracheal air cyst presented as dysphagia and caused refractory symptoms despite conservative treatments, such as proton pump inhibitors. The current case demonstrates that asymptomatic lesions can become problematic over time. Radiological evaluation of these cases is mandatory for diagnosis. .The treatment of choice is a surgical resection, even when asymptomatic.

\section{References}

1. Berrocal T, Madrid C, Novo S, et al. Congenital anomalies of the tracheobronchial tree, lung, and mediastinum: Embryology, radiology, and pathology. RadioGraphics 2004;24(1):e17-e17.

2. Kirmani B, Kirmani B, Sogliani F. Should asymptomatic bronchogenic cysts in adults be treated conservatively or with surgery? Interact Cardiovasc Thorac Surg 2010;11(5):649-59.

3. Ribet ME, Copin MC, Gosselin B. Bronchogenic cysts of the mediastinum. J Thorac Cardiovasc Surg 1995;109(5):1003-10. 
4. Kumar A, Aggarwal S, Halder S, Kumar S, Khilnani GC. Thoracoscopic excision of mediastinal bronchogenic cyst: a case report and review of literature. Ind J Chest Dis Allied Sci 2003;45:199-201.

5. Bush A. Congenital lung disease: a plea for clear thinking and clear nomenclature. Pediatr Pulmonol 2001;32:32837.

6. Quezada Salazar CA, Navarrete Arrellano M. Quiste broncogénico, diagnóstico prenatal. Bol Med Hosp Infant Mex 2005;62:202-6.

7. Stern R. Anomalías congénitas. Tratado de pediatría Nelson, 19a ed. Sección 3, vol. II. Madrid: Elsevier; 2006:1391-5.

8. Ozel SK, Kazez A, Koseogullari AA, Akpolat N. Scapular bronchogenic cyst in children: case report and review of the literature. Pediatric Surg Int. 2005;21:8435 .

9. Kravitz R. Pediatric clinics of North America. Philadelphia: Saunders;1994:386-95.

10. Sahin N, Solak A, Genç B. A rare cause of odynophagia: infected tracheal diverticulum. Kulak Burun Bogaz Ihtis Derg 2015;25(6):126-30.

11. Choi AR, Choi SH, Kim SW, Sung DW, Rha YH. A case of recurrent respiratory infection resulting from a congenital anomaly of the bronchial tree tracheal bronchus. Korean J Pediatr 2008;51:660-4. 